\title{
A Glimpse into the Future of the Climate Regime: Lessons
}

from the REDD+ Architecture

Annalisa Savaresi

accepted for publication by RECIEL 


\begin{abstract}
In 2015, parties to the United Nations Framework Convention on Climate Change (UNFCCC) formally closed negotiations on measures to maintain and enhance the carbon storage capacity of forests in developing countries, commonly referred to as 'REDD+'. This unusual and largely symbolic gesture seemingly signals that UNFCCC parties consider the international set of rules on REDD+ a 'job done', at least for the time being. This article reflects on the outcome of these negotiations and on the related law-making process, arguing that REDD+ may be regarded as the first ripe fruit in the pledge-and-review architecture recently enshrined in the Paris Agreement. REDD+ is therefore used in this article as a lens to understand how the new architecture for climate change governance may work, as well as challenges facing its implementation. In doing so, the article aims to shine a light on the path ahead for the Paris Agreement, making predictions on challenges likely to emerge with its implementation, the solutions that may be adopted, as well as areas where more international rules may be needed.
\end{abstract}




\title{
A Glimpse into the Future of the Climate Regime: Lessons from the REDD+ Architecture
}

\author{
Annalisa Savaresi ${ }^{*}$
}

\section{INTRODUCTION}

The Paris Agreement ${ }^{1}$ adopted in December 2015 enshrines and perfects in treaty form the bottom-up 'pledge-and-review' ${ }^{2}$ architecture that emerged since the ill-fated fifteenth Conference of the Parties (COP) to the United Nations Framework Convention on Climate Change $^{3}$ (UNFCCC) in 2009. ${ }^{4}$ This architecture relies on parties unilaterally declaring the action they intend to undertake to reduce their emissions, which is in turn to be subjected to a review process. In this context, the international climate change bureaucracy works as a notary collecting, and eventually enabling the review of the implementation of parties' pledged action. This bottom-up architecture leaves a very wide margin of discretion to States on how to contribute to the endeavour of tackling climate change. As such, there is a stark contrast between this new architecture and the 'targets-and-timetables' one embedded in the Kyoto Protocol, ${ }^{5}$ which contemplates specific emissions targets for some parties, as well as timetables for their achievement, and a procedure to sanction lack of compliance.

\footnotetext{
* Corresponding author.

Email: Annalisa.Savaresi@ed.ac.uk

${ }^{1}$ Paris Agreement, (Paris, 12 December 2015; not yet in force).

${ }^{2}$ The conceptualization of a pledge-and-review approach to climate governance is operated in the work of Daniel Bodansky; see: D. Bodansky, 'The Emerging Climate Change Regime' 20 Annual Review of Energy and the Environment (1995), 425; D. Bodansky and E. Diringer, 'Towards and Integrated Multi-Track Climate Framework' (Pew Center on Global Climate Change, 2007); D. Bodansky and E. Diringer, 'The Evolution of Multilateral Regimes: Implications for Climate Change' (Pew Center on Global Climate Change, 2010 ); D. Bodansky, 'A Tale of Two Architectures: The Once and Future U.N. Climate Change Regime', in: H. Koch et al. (eds.), Climate Change and Environmental Hazards Related to Shipping: An International Legal Framework (Brill, 2012), 35; and D. Bodansky, 'The Durban Platform: Issues and Options for a 2015 Agreement' (Centre for Climate and Energy Solutions, 2012).

${ }^{3}$ United Nations Framework Convention on Climate Change (New York, 9 May 1992; in force 21 March 1994) ('UNFCCC').

${ }^{4}$ UNFCCC, Decision 2/CP.15, Copenhagen Accord, (UN Doc. FCCC/CP/2009/11/Add.1, 30 March 2010).

${ }^{5}$ Kyoto Protocol to the United Nations Framework Convention on Climate Change (Kyoto, 11 December 1997 , in force 16 February 2005) ('Kyoto Protocol').
} 
While the adoption of a new approach to international climate governance was a matter of necessity, given the toppling of the approach embedded in the Kyoto Protocol, ${ }^{6}$ the recent adoption of the Paris Agreement calls for a reflection on the challenges that may be encountered in operationalizing a bottom-up pledge-and-review architecture. In this connection, there is no need to look much further afield. Between 2005 and 2015, UNFCCC parties have built a bottom-up, pledge-and-review architecture to address emissions from the forest sector in developing countries, ${ }^{7}$ commonly referred to with the acronym 'REDD+'.

The REDD+ architecture aims to enable developing countries to reduce forest emissions (by cutting down deforestation, forest degradation and sustainable forest management) and increase forest carbon sequestration (through afforestation and reforestation) on a voluntary basis. ${ }^{8}$ According to its early proponents, REDD+ was expected to draw 'developing country Parties towards emission reductions', by means of an 'equitable expansion of the market systems initiated following the Kyoto Protocol'. ${ }^{9}$ More specifically, the REDD+ architecture was expected to establish an international system enabling developing countries to reduce emissions on a voluntary basis, with developed countries providing them with the finance to do so, while appropriating carbon offsets, against the backdrop of the targets and timetables embedded in the Kyoto Protocol. ${ }^{10}$ The rationale was to reduce emissions in what seemed at the time a relatively cheap, fast and cost-effective way, in a sector that required little

\footnotetext{
${ }^{6}$ As argued for example in D. Bodansky, 'W[h]ither the Kyoto Protocol? Durban and Beyond' (Harvard Project on Climate Agreements, 2011).

${ }^{7}$ The Fifth Assessment Report of the Intergovernmental Panel on Climate Change (IPCC) estimates the share of anthropogenic greenhouse gas emissions from the agriculture, forestry and other land use sector at around $21 \%$. IPCC, 'Summary for Policymakers', in: O. Edenhofer et al. (eds.), Climate Change 2014: Mitigation of Climate Change. Contribution of Working Group III to the Fifth Assessment Report of the Intergovernmental Panel on Climate Change (Cambridge University Press, 2014), 1, at 7.

${ }^{8}$ The acronym stands for Reducing Emissions from Deforestation and forest Degradation in developing countries, and the scope of activities covered was progressively expanded to cover also the role of conservation, sustainable management of forests and enhancement of forest carbon stocks in developing countries (hence the '+'). See UNFCCC, Decision 1/CP.16, The Cancun Agreements: Outcome of the Work of the Ad Hoc Working Group on Long-term Cooperative Action under the Convention (UN Doc. FCCC/CP/2010/7/Add.1, 15 March 2011), at paragraph 70 .

${ }^{9}$ See Submission by Costa Rica and Papua New Guinea, supported by Bolivia; Central African Republic; Chile; Congo; Democratic Republic of the Congo; Dominican Republic; and Nicaragua in: UNFCCC, Reducing Emissions from Deforestation in Developing Countries. Approaches to Stimulate Action: Submission from Parties. (UN Doc. FCCC/CP/2005/MISC.1, 11 November 2005), Annex, at 7-8.

${ }^{10}$ Kyoto Protocol, n. 5 above, Annex B.
} 
technology and finance, in a relatively small group of countries. ${ }^{11}$ However, ten years of negotiations have delivered an architecture that markedly differs from that envisioned by its early proponents, ${ }^{12}$ and is not linked to the targets-and-timetables architecture embedded in the Kyoto Protocol. Still, this unprecedented international environmental governance experiment has broken new ground on several counts. ${ }^{13}$ It has opened the way to reducing emissions in developing countries in a sector that has long caused much heartache to climate change scientists and policy makers alike. ${ }^{14}$ More importantly for the present purposes, REDD + may be regarded as the first ripe fruit in the pledge-and-review architecture for international climate change governance.

This article argues that experience accrued with the design and implementation of the REDD + architecture holds important lessons for the Paris Agreement. It therefore uses REDD + as a lens to understand how a pledge-and-review architecture to climate change governance may work, the challenges that may be encountered in its implementation, as well as the means that may be used to overcome these. The article opens by introducing the bottom-up pledge-and-review architecture for REDD+ and its relationship with the one sketched in the Paris Agreement. It then goes on to consider what the REDD+ experience reveals about the implementation of a bottom-up pledge-and-review architecture to climate change governance, and the challenges it poses. This exercise focuses on three elements: (i) the establishment of conditions for a market-based approach to climate change mitigation; (ii) the framework to review the implementation of parties' obligations; (iii) and the management of the related international law-making process. The conclusions reflect on lessons that may

\footnotetext{
${ }^{11}$ See for example N. Stern, The Economics of Climate Change: The Stern Review (Cambridge University Press, 2007), at 26 .

${ }^{12}$ Negotiations on methodological guidance on REDD+ were formally closed in June 2015, see: UNFCCC, Methodological Guidance for Activities Relating to Reducing Emissions from Deforestation and Forest Degradation and the Role of Conservation, Sustainable Management of Forests and Enhancement of Forest Carbon Stocks in Developing Countries. Draft Conclusions Proposed by the Chair (UN Doc. FCCC/SBSTA/2015/L.5, 9 June 2015).

${ }^{13}$ For a comprehensive review, see C. Voigt (ed.), Research Handbook on REDD+ and International Law (Edward Elgar, 2016).

${ }^{14}$ As explained, for example, in Z.E. Bailey, 'Sink That Sank The Hague: A Comment on the Kyoto Protocol', 16:1 Temple International and Comparative Law Journal (2002), 103; and E. Trines, 'History and Context of LULUCF in the Climate Regime', in: C. Streck et al. (eds.), Climate Change and Forests. Emerging Policy and Market Opportunities (Brookings Institution Press, 2008), 33. The problematic nature of this sector is confirmed by the fact that the IPCC has prepared two special reports on land uses, one under preparation, and another published in 2000: see R.T. Watson et al. (eds.), Land Use, Land-Use Change, and Forestry. A Special Report of the IPCC (Cambridge University Press, 2000).
} 
be drawn from the design and the implementation of the REDD+ architecture for the long regulatory journey that parties to the climate regime are about to embark on to operationalize the Paris Agreement.

\section{BOTTOM-UP PLEDGE-AND-REVIEW ARCHITECTURES}

The Paris Agreement has brought to completion the pledge-and-review architecture that first emerged in 2009, by imposing an obligation on all parties to prepare, communicate and maintain successive nationally determined contributions (NDCs) and to pursue mitigation activities at the national level. ${ }^{15}$ This architecture hinges on obligations of conduct, ${ }^{16}$ which require all parties to submit information on how they intend to reduce their emissions, and by how much. ${ }^{17}$ While no format for (intended) NDCs ${ }^{18}$ could be agreed ahead of the adoption of the Paris Agreement, the conference of the parties serving as the meeting of the parties is expected to adopt specific guidance on this issue. ${ }^{19}$ The Paris Agreement furthermore establishes the premises for the creation of a machinery to review parties' efforts periodically, both at the individual ${ }^{20}$ and at the aggregate level. ${ }^{21}$ Implementation of the agreement will also be assisted by an expert-based, facilitative compliance mechanism. ${ }^{22}$

It is already abundantly clear that the obligations of conduct that make up the pledge-andreview architecture of the Paris Agreement are rather different in nature from the obligations of result enshrined in the emissions targets for developed countries under the Kyoto

\footnotetext{
${ }^{15}$ Paris Agreement, n. 1 above, Articles 3 and 4.2.

${ }^{16}$ As argued also D. Bodansky, 'The Legal Character of the Paris Agreement', 25:2 Review of European, Comparative and International Environmental Law (2016); and A. Savaresi, 'The Paris Agreement: A Rejoinder', EJIL: Talk! (16 February 2016), found at: <http://www.ejiltalk.org/the-paris-agreement-arejoinder/>.

${ }^{17}$ Paris Agreement, n. 1 above, Article 4.2.

${ }^{18}$ UNFCCC Parties decided to submit intended nationally determined contributions (INDC) ahead of the adoption of the Paris Agreement, see UNFCCC, Decision 1/CP.19, Further Advancing the Durban Platform (UN Doc. FCCC/CP/2013/10/Add. 1, 31 January 2014), at 2.

${ }_{19}$ Paris Agreement, n. 1 above, Article 4.13; and UNFCCC, Decision 1/CP.21, Adoption of the Paris Agreement (UN Doc. FCCC/CP/2015/10, Add.1, 29 January 2016), at paragraph 31.

${ }^{20}$ Paris Agreement, n. 1 above, Article 13.

${ }^{21}$ Ibid., Article 14.

${ }^{22}$ Ibid., Article 15. See also C. Voigt, "The Compliance and Implementation Mechanism of the Paris Agreement', 25:2 Review of European, Comparative and International Environmental Law (2016).
} 
Protocol. ${ }^{23}$ These targets are assisted by a rich set of obligations of conduct concerning the reporting of information, with the aim to enable the review of implementation and compliance. While the implementation of the Kyoto Protocol has delivered disappointing results, these are largely related to its approach to differentiation and to parties' faltering political will, ${ }^{24}$ rather than to the targets-and-timetables architecture ex se. If anything, the Kyoto Protocol's architecture for the review of implementation and compliance is rather robust, especially by the standards of an international environmental agreement. ${ }^{25}$

It remains to be seen whether the new pledge-and-review approach to international climate change governance enshrined in the Paris Agreement will deliver the hoped for results and will be sustained by parties' political will over time. ${ }^{26}$ The details of this architecture are yet to be designed by the body entrusted to prepare for the entry into force of the Paris Agreement and by the UNFCCC subsidiary bodies, in what can be expected to be a lengthy regulatory process. ${ }^{27}$

REDD + may be regarded as the first ripe fruit of this new architecture. UNFCCC developing country parties are merely encouraged, and not obliged, to undertake REDD+ activities. ${ }^{28}$ However, if they decide to do so, they are required to comply with a set of obligations of

\footnotetext{
${ }^{23}$ Kyoto Protocol, n. 5 above, Article 3.1 and Annex B. For a reflection on the differences between these obligations, see: R. Wolfrum, 'Obligation of Result Versus Obligation of Conduct: Some Thoughts About the Implementation of International Obligations', in: M.H. Arsanjani and J. Cogan (eds.), Looking to the Future: Essays on International Law in Honor of W. Michael Reisman (Martinus Nijhoff, 2010), 363; and P. Dupuy, 'Reviewing the Difficulties of Codification: On Ago's Classification of Obligations of Means and Obligations of Result in Relation to State Responsibility', 10:2 European Journal of International Law (1999), 371.

${ }^{24}$ As pointed out also in L. Rajamani, 'From Berlin to Bali and beyond: Killing Kyoto Softly 57:4 International and Comparative Law Quarterly (2008), 909; and D. Bodansky, n. 6 above.

${ }^{25}$ As argued for example also in R. Lefeber and S. Oberthür, 'Key Features of the Kyoto Protocol's Compliance System', in: J. Brunnée et al. (eds.), Promoting Compliance in an Evolving Climate Regime (Cambridge University Press, 2011), 77; and M. Doelle, 'Compliance and Enforcement in the Climate Change Regime', in: E. Hollo et al. (eds.), Climate Change and the Law (Springer, 2012), 165.

${ }^{26}$ Some early reflections in this connection are provided in A. Savaresi and F. Sindico, 'The Role of Law in a Bottom-up International Climate Governance Architecture: Early Reflections on the Paris Agreement', 6 Questions of International Law (2016), 1; H. van Asselt, 'International Climate Change Law in a Bottom-up World', 6 Questions of International Law (2016), 5; and C. Voigt, 'The Paris Agreement: What Is the Standard of Conduct for Parties?', 6 Questions of International Law (2016), 17.

${ }^{27}$ As detailed in Decision 1/CP.21, n. 19 above, at paragraphs 26, 28, 31, 34, 92-95 and 100-102 for the Ad Hoc Working Group on the Paris Agreement; and 29, 34, 37, 39-41, 58, 68, 76-77 and 101 for the Subsidiary Body for Implementation and the Subsidiary Body for Scientific and Technological Advice.

${ }^{28}$ Decision 1/CP.16, n. 8 above, at paragraph 71.
} 
conduct concerning the reporting of information, which are subjected to a review process. ${ }^{29}$ If they intend to seek results-based payments, they are furthermore subjected to an additional layer of reporting obligations and to an additional review process, which is geared to verifying the delivery of mitigation outcomes. ${ }^{30}$

With the adoption of the Paris Agreement, the nature of REDD+ has changed dramatically, from that of a means to merely enable developing countries to reduce emissions on a voluntary basis, to a means to enable them to comply with the pledges made in their NDCs. Yet there remains remarkable uncertainty on where the finance to carry out REDD+ may come from. In the mind of some of its early proponents, an international market-based architecture to support REDD+ was expected to emerge, creating conditions for investors to finance REDD+ activities, while ensuring the carbon integrity of emission reductions produced, as well as the cost-effective allocation of the resources available. ${ }^{31}$ Nevertheless, this architecture has not materialized. Instead, parties have recognized that REDD+ finance may come from a variety of sources, ${ }^{32}$ and, in practice, has so far been disbursed beyond market-based logics and the institutional remit of the UNFCCC.

Even if, when compared with the stalemate that affected international climate change governance for many years, REDD+ negotiations represented an area of relative progress, the related law-making process has been far from straightforward, and may rather be likened to an odyssey. ${ }^{33}$ During this adventurous journey, the law on REDD + has evolved in unpredicted directions, pulverizing into a myriad of uncoordinated arrangements, which may have become a hindrance to ensuring the comparability of parties' efforts and their carbon integrity.

\footnotetext{
${ }^{29}$ Ibid., at paragraph 73 .

${ }^{30}$ These are outlined in UNFCCC, Decision 13/CP.19, Guidelines and Procedures for the Technical Assessment of Submissions from Parties on Proposed Forest Reference Emission Levels and/or Forest Reference Levels (UN Doc. FCCC/CP/2013/10/Add. 1, 31 January 2014); and Decision 14/CP.19, Modalities for Measuring, Reporting and Verifying (UN Doc. FCCC/CP/2013/10/Add. 1, 31 January 2014).

31 As envisioned for example in J. Eliasch, Climate Change: Financing Global Forests. The Eliasch Review (Earthscan, 2008).

${ }^{32}$ See Decision 2/CP.17, n. 38 above, at paragraph 65.

${ }^{33}$ See A. Savaresi, 'Forests and Climate Change: An International Law-Making Odyssey', Presentation at the Workshop on Smart Mixes in Relation to Forest and Climate Change Governance, University of Amsterdam, 45 February 2015.
} 
There therefore seem to be three key areas where the experience with REDD+ may provide useful lessons for the implementation of the architecture sketched under the Paris Agreement. The first are the regulatory challenges associated with crafting an international legal framework for a market-based approach to climate change mitigation in the context of a bottom-up pledge-and-review architecture. The second relates to the design of obligations for the review of implementation of parties' action. The third are challenges associated with the management of the law-making process itself. The following sections look at these three matters in turn, highlighting the challenges encountered in the construction and implementation of the REDD+ architecture and the lessons they may hold for the implementation of the Paris Agreement.

\section{A MARKET BASED APPROACH TO CLIMATE CHANGE MITIGATION}

Ever since the dawn of international climate change governance, States have toyed with idea of adopting a market-based approach to facilitate the reduction of emissions and gather the finance necessary to do so, through the involvement of private investors. ${ }^{34}$ For better or worse, emissions trading is the policy tool upon which they have decided to focus their attention.

The top-down targets-and-timetables architecture for international climate change governance enshrined in the Kyoto Protocol relied on a market-based approach to climate change mitigation. While the Protocol did not prescribe the creation of a global carbon market, its overall architecture largely hinged on the idea that such a market would materialize, kick-starting the process for its realization, by encouraging the use of markedbased approaches to stimulate climate change mitigation. ${ }^{35}$ The Kyoto Protocol did so by establishing the so-called flexibility mechanisms to help parties achieve their targets, consisting of international emission trading, as well as mechanisms to enable joint

\footnotetext{
${ }^{34}$ As reported for example in D.M. Driesen, 'Free Lunch or Cheap Fix?: The Emissions Trading Idea and the Climate Change Convention', 26:1 Boston College Environmental Affairs Law Review (1998), 1.

${ }^{35}$ As noted also in H. van Asselt, 'The Design and Implementation of Greenhouse Gas Emissions Trading', in: C. Carlarne et al., The Oxford Handbook of International Climate Change Law (Oxford University Press, 2016), 336.
} 
implementation between developed countries, and between developed and developing countries respectively. ${ }^{36}$ Much of the regulatory activity carried out under the Kyoto Protocol was aimed at enabling the operation of these mechanisms. This regulatory framework details the conditions for the creation of credits and their trading, as well as to ensure that traded units are equivalent in nature and value (fungibility), and the product of genuine and comparable emission reduction activities (carbon integrity). The related rules have been developed by subsidiary bodies established under the Kyoto Protocol, which have maintained overall control of the rule-making process, as well as of the functioning of the flexibility mechanisms.

Like the Kyoto Protocol, the Paris Agreement leaves open the possibility for parties to reduce their emissions by means of joint implementation. ${ }^{37}$ Yet, drawing an international law framework for a market-based approach to climate change mitigation in the context of a bottom-up, pledge-and-review architecture seems to raise specific regulatory challenges. These challenges largely relate to the need to create the regulatory conditions for investors to finance emission reduction activities, to ensure the carbon integrity of emission reductions produced, as well as a cost-effective allocation of the resources available.

These challenges are well exemplified by the REDD+ architecture. When compared with the flexibility mechanisms established under the Kyoto Protocol, the REDD+ architecture is rather fragmented and patchy. UNFCCC parties are free to engage in REDD+ activities, and to resort to market-based approaches to support them, if they so choose. ${ }^{38}$ Initially, REDD+ finance was largely expected to mainly derive from the creation of a new commodity, i.e. REDD + forest carbon credits. These credits were to be purchased by developed countries seeking to meet their emission reduction obligations, as well as by non-State actors with emission reduction obligations under domestic and/or regional law. The adoption of a market-based approach to REDD+, however, would require international rules for creating a demand for REDD+ credits, as well rules on how such credits would be created, and the

\footnotetext{
${ }^{36}$ Kyoto Protocol, n. 5 above, Articles 6, 12 and 17.

${ }^{37}$ UNFCCC, n. 3 above, Article 6.2 and 6.4.

${ }^{38}$ See UNFCCC, Decision 2/CP.17, Outcome of the Work of the Ad Hoc Working Group on Long-term Cooperative Action under the Convention, (UN Doc. FCCC/CP/2011/9/Add.2, 11 December 2011), at paragraph 65.
} 
conditions for their tradability on a like-to-like basis across jurisdictions. Yet, at present, these rules simply do not exist.

The only proxy for such rules are those established in the context of the Clean Development Mechanism (CDM) under the Kyoto Protocol. ${ }^{39}$ The CDM enables actors in developing countries to carry out climate change mitigation projects on a voluntary basis, and to create emission reduction credits, that may be purchased by developed country parties to achieve compliance with their targets under the Kyoto Protocol. In this transaction, developed countries obtain offsets they can use to comply with their obligations, whereas developing countries indirectly receive finance, as well as technology and know-how. This win-win scenario was expected to lead to emission reductions, while enabling developed countries to comply with their targets under the Kyoto Protocol, as well as their obligations concerning the provision of assistance to developing ones. ${ }^{40}$ These expectations, however, have been largely frustrated. The CDM viability relied upon the widespread uptake of carbon markets as a climate policy tool, which has not materialized. ${ }^{41}$ The numerous challenges facing the operation of existing carbon markets have induced a collapse in the price of carbon, and, consequently, in the demand for offsets. ${ }^{42}$ The desirability of offsets from the perspective of carbon integrity has furthermore been increasingly questioned. ${ }^{43}$ Together these factors have greatly undermined the CDM, prompting a lively, albeit inconclusive, debate over its reform. ${ }^{44}$

Whereas in the beginning UNFCCC parties contemplated the inclusion of REDD+ activities in the scope of the $\mathrm{CDM}^{45}$ - which already includes afforestation and reforestation activities ${ }^{46}$

\footnotetext{
${ }^{39}$ Kyoto Protocol, n. 5 above, Article 12.

${ }^{40}$ UNFCCC, n. 3 above, Article 4.3.

${ }^{41}$ See the dataset available at: <http://www.carbonpricingleadership.org/who/>.

${ }^{42}$ As reported for example in A. Kossoy et al., State and Trends of Carbon Pricing 2015 (World Bank, 2015).

${ }^{43}$ See for example M. Gillenwater and S. Seres, The Clean Development Mechanism. A Review of the First International Offset Program (Pew Center on Global Climate Change, 2011).

${ }^{44}$ High-Level Panel on the CDM Policy Dialogue, Climate Change, Carbon Markets and the CDM: A Call to Action (2012).

${ }^{45}$ Ibid., at 31. See also the collection of suggestions reviewed in C. Parker et al., The Little REDD+Book: A Guide to Governmental and Non-Governmental Proposals for Reducing Emissions from Deforestation and Degradation (Global Canopy Programme, 2009).

${ }^{46}$ UNFCCC, Decision 16/CMP.1 Land use, Land-use Change and Forestry (UN Doc.

FCCC/KP/CMP/2005/8/Add.3, 30 March 2006) Annex, at 13.
} 
- they progressively set aside this option. Instead, they decided to address specific monitoring and verification challenges associated with the forest sector by adopting a 'jurisdictional' approach to REDD+. Pursuant to this approach, REDD+ activities are to be measured and reported at the national level, and are anchored to State obligations. ${ }^{47}$ When compared with the 'project-based' approach of the $\mathrm{CDM},{ }^{48}$ therefore, REDD+ is markedly different, as it is States, and not project developers, who are in charge of monitoring emission reductions and of securing that REDD+ activities are carried out in line with internationally agreed requirements. Equally, transactions associated with REDD+ results-based payments are largely a matter of inter-State relations, whose ultimate parties are State actors and/or institutions performing as intermediaries between them. ${ }^{49}$ In this scenario, should REDD+ activities generate any credits at all, UNFCCC parties providing finance and those providing forest carbon credits would enter into relationships akin to bilateral investment and characterized by a do ut des ethos. Still, UNFCCC rules say nothing on the possible transfer of REDD+ credits or offsets. This issue is entirely left to bilateral dealings either between parties, and/or between parties and institutions providing REDD+ finance. This arrangement raises some concerns over unit transfers and the risk of double counting. While for the time being this risk largely remains hypothetical, if a market-based approach to REDD+ is widely adopted, it would seem necessary for UNFCCC parties to consider the means to tackle these risks.

One expedient forum to do so may be the new sustainable development mechanism established under the Paris Agreement. ${ }^{50}$ Little is presently known on how this new mechanism for the joint implementation of mitigation activities will work, other than the fact that joint implementation activities should 'apply robust accounting to ensure, inter alia, the avoidance of double counting, ${ }^{51}$ It is possible that REDD+ is included among eligible

\footnotetext{
${ }^{47}$ UNFCCC, Decision 2/CP.13, Reducing Emissions from Deforestation in Developing Countries: Approaches to Stimulate Action (UN Doc. FCCC/CP/2007/6/Add.1, 14 March 2008), Annex, at paragraph 7.

${ }^{48}$ On the possibility of moving beyond a project-based approach in the context of the CDM, see High-Level Panel on the CDM Policy Dialogue, n. 44 above.

${ }^{49}$ As argued also in A. Dibler et al., 'Consolidated Guide to the REDD+ Rules Under the UNFCCC' (Baker \& McKenzie, 2014), at 42.

${ }^{50}$ Paris Agreement, n. 1 above, Article 6.4(c).

${ }^{51}$ Paris Agreement, n. 1 above, Article 6.2.
} 
activities under the sustainable development mechanism, and that rules concerning the tradability of credits are developed in that context.

It is important to note, nevertheless, that some parties have expressed reservations on including REDD+ credits in carbon markets, fearing that their abundant availability would swamp already frail carbon markets. ${ }^{52}$ Some developing country parties furthermore resist the idea that emission reductions carried out in developing countries be credited to developed ones, ${ }^{53}$ whereas others object to the commodification of forest carbon altogether. ${ }^{54}$ While it remains to be seen whether these fundamental objections will continue to be made after the adoption of the Paris Agreement, for the time being, a non-market-based approach to REDD+ has prevailed. In this context, developed countries get nothing in return for financing emissions reductions in developing ones, other than compliance with their general obligations to assist them in tackling climate change. ${ }^{55}$ As a result, inter-State support for REDD+ activities is akin to development assistance. ${ }^{56}$ The contrast with the CDM ethos is manifest: while, at least in theory, the CDM generates revenue through the sale of credits on carbon markets, finance for REDD+ is the result of development assistance arrangements between parties willing to carry out REDD+ activities and those State and non-State actors willing to support these.

This 'aid-ification' of REDD+ was largely necessitated by events. Given that a global carbon market does not exist, and that the main carbon market in existence - the European Union emission trading system - does not allow the trading of REDD+-derived credits, there was no

\footnotetext{
${ }^{52}$ See, e.g., Commission of the European Communities Communication of 17 October 2008 on Addressing the Challenges of Deforestation and Forest Degradation to Tackle Climate Change and Biodiversity Loss, $\operatorname{COM}(2008) 645$, at 10.

${ }^{53}$ See, e.g., Joint Statement Issued at the Conclusion of the $16^{\text {th }}$ Basic Ministerial Meeting on Climate Change. Governments of Brazil, South Africa, India and China, Meeting in Foz do Iguaçu, Brazil (15-16 September 2013), found at: $<$ https://www.environment.gov.za/mediarelease/16thbasic_ministerialmeeting_climatechange> ${ }^{54}$ See, e.g., the submission by the Plurinational State of Bolivia in: Matters Relating to Methodological Guidance for Non-market Based Approaches, such as Joint Mitigation and Adaptation Approaches for the Integral and Sustainable Management of Forests (26 March 2014), found at: $<$ http://www4.unfccc.int/submissions/Lists/OSPSubmissionUpload/12_15_130452435512456801Bolivia_NMBA.pdf $>$.

${ }^{55}$ UNFC CC, n. 3 above, Article 4.3.

${ }^{56}$ On the 'aid-ification' of REDD+ see, e.g., A. Angelsen and D. McNeill, 'The Evolution of REDD+', in A. Angelsen et al. (eds.), Analysing REDD+: Challenges and Choices (Center for International Forestry Research, 2012), 31, at 39 .
} 
other option but for REDD+ finance to come from aid budgets. While this may have been an acceptable interim solution to build the conditions to carry out REDD+ activities, in the long run there is a need to ensure the involvement of the private sector to scale up REDD+ finance. ${ }^{57}$ The adoption of a market-based approach, and the inclusion of REDD + credits in existing emission trading schemes, would seem to be the obvious solution. Yet, no international rules on how this may happen have been agreed, and presently there is little clarity on the source of result-based payments for REDD+ in the long run.

In sum, the experience with REDD+ seems to suggest that, if parties decide to adopt a market-based approach to finance climate change mitigation endeavours, they need to establish a clear set of rules applicable to all parties from the outset. These rules should enable the tradability of credits across jurisdictions, and ensure the carbon integrity of emission reductions. The experience with REDD+ sets a limited precedent in this connection, and clearly demonstrates the challenges associated with a bottom-up regulatory framework that leaves these important details to the contracting between parties and/or institutions disbursing REDD+ payments. Parties' obligations concerning the provision of information and the review of implementation and compliance play a pivotal role in this regard, as explained next.

\section{THE REVIEW OF IMPLEMENTATION}

The provision of information is a crucial ingredient of international environmental agreements, both to ensure the monitoring of problems that parties seek to tackle - in the case of the climate regime, the emissions of greenhouse gases and their impacts - as well as to review parties' adherence to the obligations they have undertaken. ${ }^{58}$ The mechanisms for the review of implementation and compliance tend to differ, depending on the nature of parties' obligations. This is well exemplified by the climate regime.

\footnotetext{
${ }^{57}$ As suggested, for example, in C. Streck and C. Parker, 'Financing REDD+', in: A. Angelsen et al., n. 56 above, 111.

${ }^{58}$ See, e.g., D.G. Victor et al. (eds.), The Implementation and Effectiveness of International Environmental Commitments (MIT Press, 1998).
} 
The UNFCCC and the Kyoto Protocol deploy different systems to review the implementation of parties' obligations. Under the Kyoto Protocol, the reporting of information, and the process for the review of implementation of parties' obligations, are geared towards ascertaining fulfilment of developed countries' obligations of results - i.e. the emission reduction and limitation targets enshrined in Annex B of the Protocol. The Kyoto Protocol's Compliance Committee has performed an important role in overseeing parties' adherence to reporting obligations. ${ }^{59}$

Conversely, under the UNFCCC the reporting of information and its review are not aimed to assess compliance with obligations of result. Instead, UNFCCC parties are subjected to facilitative processes to provide information on the implementation of their obligations, which do not attach consequences to instances of lack of compliance. Furthermore, developed and developing country parties' reporting obligations remain differentiated in nature and kind, and so are the related review processes. ${ }^{60}$ While implementation of these arrangements has just begun, it has already evidenced some shortcomings. ${ }^{61}$ First, the lack of a standard template to report pledged mitigation action before 2020 has hindered comparison between parties' efforts. Second, the review process does not provide means to 'ratchet up' ambition over time. Third, developing countries have struggled to comply with their increased reporting obligations, ${ }^{62}$ thus drawing attention to the need for dedicated assistance and capacity building. More generally, the reporting of information in a transparent and complete manner is predictably harder where no standard definitions and/or methods exist. ${ }^{63}$

These shortcomings are exemplarily demonstrated by REDD+. Reporting obligations to ensure the carbon integrity of emission reductions and removals associated with REDD+ activities are additional to those under the UNFCCC. Still, compared with the rules on the

\footnotetext{
${ }^{59}$ As argued for example in R. Lefeber and S. Oberthür, n. 25 above; and M.Doelle, n. 25 above.

${ }^{60}$ Decision 1/CP.16, n. 8 above, at paragraphs 44-46 and 63-64.

${ }^{61}$ As noted for example in J. Ellis and S. Moarif, Identifying and Addressing Gaps in the UNFCCC Reporting Framework (Organisation of Economic Co-operation and Development, 2015); and in Y. Dagnet et al., 'Improving Transparency and Accountability in the Post-2020 Climate Regime: A Fair Way Forward' (World Resource Institute 2015).

${ }^{62}$ As of January 2016, only 24 developing country parties have submitted their biennial update reports, whereas all developed countries parties have submitted their biennial reports.

${ }^{63}$ As reported in J. Ellis and S. Moarif, n. 61 above, at 4.
} 
reporting of emissions and removals under the Kyoto Protocol, the REDD+ framework is characterized by a 'country-driven' approach, ${ }^{64}$ hinging on rather loose reporting obligations, which leave a remarkable margin of discretion to parties. ${ }^{65}$

First, and contrary to what happened under the Kyoto Protocol, no definition of forest, or forestry activities, has been adopted for the purposes of REDD+. Allowing parties to adopt definitions of their choosing, ${ }^{66}$ however, leaves the scope of REDD+ virtually undetermined, and potentially engenders considerable inconsistencies. ${ }^{67}$ This potentially opens the way to incongruities as to what REDD+ activities are, rendering the comparison between parties' efforts rather difficult. ${ }^{68}$ To be sure, this potential exists also under the Kyoto Protocol, and has led to much debate on rules concerning the accounting of emissions from land uses. ${ }^{69}$ The related carbon integrity concerns have induced some developed countries to exclude emissions from land uses from generating credits tradable under their emission trading schemes. $^{70}$

\footnotetext{
${ }^{64}$ Decision 1/CP.16, n. 8 above, Appendix 1, at paragraph 1(c).

${ }^{65}$ UNFCCC, Decision 4/CP.15, Methodological Guidance for Activities Relating to Reducing Emissions from Deforestation and Forest Degradation and the Role of Conservation, Sustainable Management of Forests and Enhancement of Forest Carbon Stocks in Developing Countries (UN Doc. FCCC/CP/2009/11/Add.1, 30 March 2010), at paragraph 1(c-d) and 7; Decision 11/CP.19, Modalities for National Forest Monitoring Systems (UN Doc. FCCC/CP/2013/10/Add.1, 31 January 2014); and Decision 14/CP.19, n. 30 above.

${ }^{66}$ UNFCCC, Decision 12/CP.17, Guidance on Systems for Providing Information on How Safeguards Are Addressed and Respected and Modalities Relating to Forest Reference Emission Levels and Forest Reference Levels as referred to in Decision 1/CP.16 (UN Doc. FCCC/CP/2011/9/Add.2, 15 March 2012), Annex, at (d).

${ }^{67}$ As argued for example in N. Sasaki and F.E. Putz, "Critical Need for New Definitions of "Forest" and "Forest Degradation" in Global Climate Change Agreements', 2:5 Conservation Letters (2009), 226; and T. Pistorius et al., Greening REDD+ Challenges and Opportunities for Forest Biodiversity Conservation, (University of Freiburg, 2010).

${ }^{68}$ As argued also in A. Savaresi, 'Reducing Emissions from Deforestation in Developing Countries under the UNFCCC: Caveats and Opportunities for Biodiversity', 21 Yearbook of International Environmental Law (2011), 81.

${ }^{69}$ As reported in P. Iversen et al., 'Understanding Land Use in the UNFCCC' (Climate and Land Use Alliance 2014), at 24-25.

${ }^{70}$ This has consistently been the case in the European Union, see: Extended Impact Assessment on the Directive of the European Parliament and of the Council amending Directive Establishing a Scheme for Greenhouse Gas Emission Allowance Trading within the Community in Respect of the Kyoto Protocol's Project Based Mechanisms COM(2003) 403, SEC(2003) 785; Impact Assessment of the Directive of the European Parliament and of the Council Amending Directive 2003/87/EC so as to Improve and Extend the EU Greenhouse Gas Emission Allowance Trading System, COM(2008) 16, SEC(2008) 53; and Impact Assessment of Proposal for a Decision of the European Parliament and of the Council on Accounting Rules and Action Plans on Greenhouse Gas Emissions and Removals Resulting from Activities Related to Land Use, Land Use Change and Forestry, $\operatorname{COM}(2012)$ 93, $\operatorname{SWD}(2012) 40$.
} 
Second, the reporting of REDD+ activities hinges on the setting of forest reference emission levels, which are the benchmarks against which parties' performance will be assessed, taking into account historical data and emissions parties reported in the past. ${ }^{71}$ The fact that up until recently developing country parties only had very limited reporting obligations, however, entails that many do not have much historical data on their forest emissions and removals. ${ }^{72}$ There can therefore be a great deal of arbitrariness in a party's choice of its forest reference emissions level, which will be particularly difficult to assess. A 'facilitative, non-intrusive' expert assessment process $^{73}$ is meant to provide an opportunity to identify areas for technical improvement, ${ }^{74}$ but no consequences are attached to negative assessments. It is up to those disbursing REDD+ finance to make their own mind on the reliability of reference levels, based on the information emerging from assessments. This remarkable margin of discretion raises the question of how to reconcile a bottom-up approach to climate change governance with the need to ensure the carbon integrity of the results they deliver.

Third, parties have considerable discretion to choose the modalities for the measuring, reporting and verification of REDD+ emission reductions and removals. ${ }^{75}$ This is in line with the voluntary nature of REDD+ activities and with developing countries' limited obligations concerning climate change mitigation under the UNFCCC. ${ }^{76}$ Nevertheless, with the shift embedded in the Paris Agreement, whereby all parties are required to reduce their emissions and to report information on the details, ${ }^{77}$ this arrangement is likely to become inadequate.

Finally, like any other mitigation action undertaken by developing countries under the UNFCCC, the implementation of REDD+ activities is to be subjected to a facilitative consultation process aimed at enhancing transparency and contributing to capacity building in

\footnotetext{
${ }^{71}$ Decision 12/CP.17, n. 6666 above, at paragraph 9.

72 As noted for example also in C. Umemiya et al., 'Assessing Data Availability for the Development of REDDplus National Reference Levels’ 5 Carbon Balance and Management (2010), 6.

${ }^{73}$ Decision 13/CP.19, n. 30 above.

${ }^{74}$ Ibid., Annex, at paragraph 3.

${ }^{75}$ Decision 14/CP.19, n. 30 above.

${ }^{76}$ Whereas UNFCCC, n. 3 above, Article 4.1(b) in principle requires all parties to reduce their emissions, in practice this provision has been interpreted in the sense of imposing binding emission reduction obligations only on developed countries.

${ }^{77}$ Paris Agreement, n. 1 above, Article 4.
} 
developing country parties. ${ }^{78}$ This process is non-adversarial in nature and is not aimed at detecting compliance with State obligations. Rather, it is aimed at improving the understanding of parties' mitigation activities and enhancing their reporting capacity. Again, under the Paris Agreement, the adequacy of this review process will have to be scrutinized and brought into line with the new arrangements for the review of implementation and compliance made under that treaty. ${ }^{79}$ On top of the consultation process above, parties seeking results-based payments for REDD+ need to comply with additional reporting obligations, which are subjected to a separate and dedicated technical review process. ${ }^{80}$ How this process will work in practice, however, remains to be seen. ${ }^{81}$ While the review process does not contemplate any consequences for lack of compliance, it would seem plausible to expect that these will result in ineligibility to receive REDD+ payments.

Institutions entrusted with the handling of REDD+ finance are likely to play an important role in this regard. Even though formally these institutions are not part of the review process, in fact, they will make their funding decisions on the basis of it, de facto applying consequences to lack of or poor compliance with parties' reporting obligations. Again, this architecture remains to be tested in practice. Still, it already seems clear that the bulk of finance for REDD+ is likely to be disbursed beyond the institutional remit of the climate regime. ${ }^{82}$ As a result of this arrangement, crucial inter-State cooperation decisions are likely to be made beyond the institutional remit and scrutiny of the climate regime. While this is not ex se a tragedy, ${ }^{83}$ the long-term implications of this approach for the overall carbon integrity of climate change action remain to be seen.

To sum up, the legal framework for the review of the implementation of parties' obligations in relation to REDD+ remains sketchy, and largely untested in practice. The nature of parties' obligations on REDD+ is yet to be understood, though it seems clear that at least some

\footnotetext{
${ }^{78}$ Decision 1/CP.16, n. 8 above, at paragraphs 56-62 and Decision 14/CP.19, n. 30 above.

${ }^{79}$ Paris Agreement, n. 1 above, Articles 13 and 15.

${ }^{80}$ Decision $14 /$ CP. 19 , n. 30 above at paragraphs 7-14.

81 The reports are available at: <http://unfccc.int/national_reports/nonannex_i_natcom/reporting_on_climate_change/items/8722.php >.

${ }^{82}$ Data on sources of REDD + finance may be accessed at: $<$ http://www.climatefundsupdate.org/themes/redd $>$.

${ }^{83}$ As argued also in H. van Asselt and C. McDermott, 'The Institutional Complex of REDD+: A Benevolent Jigsaw?' in: C. Voigt, n. 13 above, 63.
} 
elements of this architecture have progressively hardened in obligations that now encumber parties wishing to seek results-based payments for REDD+ activities. Yet, under the Paris Agreement, specific carbon integrity considerations are associated with verifying that countries undertaking REDD+ activities actually reduce their emissions in line with their NDCs, regardless of whether or not they ask to receive results-based payments. Whether the rules and processes for the review of the implementation of REDD+ activities are suited to deliver this certainty seems doubtful. This in turn raises questions over the desirability of creating tradable credits associated with activities whose carbon integrity may be questionable.

The Paris Agreement provides no explicit solutions to these questions. In its sole reference to $\mathrm{REDD}+$, the agreement conveys parties' lack of appetite to re-engage in law-making on the issue, and to reconsider what already agreed, in spite of its perceived shortcomings. ${ }^{84}$ Still, implementation of the Paris Agreement is expected to establish a level playing field, whereby all parties will report their emission reductions on equal terms and will be subjected to the same review processes. ${ }^{85}$ This guidance may also include specific new rules concerning emissions from the land sector. The history of existing rules suggests that devising a unitary format to measure, report and verify emissions in this sector is likely to be hard and timeconsuming. ${ }^{86}$ Experience accumulated with REDD + thus far, however, indicates that also a country-driven approach to the measuring, reporting and verification presents challenges.

Implementation of the Paris Agreement is furthermore expected to deliver a unitary system to review implementation and compliance, building upon the extant framework established under the UNFCCC. ${ }^{87}$ Even though in the short- to medium-term some differentiation is likely to remain, it would seem vital that over time all parties move towards a robust framework for reporting and reviewing the implementation of their obligations, along lines similar to those designed under the Kyoto Protocol.

\footnotetext{
${ }^{84}$ Paris Agreement, n. 1 above, Article 5.2.

${ }^{85}$ Ibid., Article 13.

${ }^{86}$ See, e.g., Z.E. Bailey, n. 14 above ; and E. Trines, n. 14 above.

${ }^{87}$ Decision 1/CP.21, n. 19 above, at paragraph 21.
} 
Building upon the rules in the Kyoto Protocol would have two main advantages. First, it would secure that parties capitalize on experience accumulated with the implementation of extant rules and review processes, adjusting them to the specific regulatory needs arising under the Paris Agreement. Second, it would cater for the needs of parties wishing to avail themselves of market-based approaches to climate change mitigation, thus enabling tradability of credits across jurisdictions. Lastly, the experience with REDD+ signals that it would be ill-advised to leave the definition of the fundamental traits of the architecture for the reporting of information and the review of implementation to the free contracting between parties. There are, in other words, strong arguments to safeguard intergovernmental control over the law-making process, as the next section explains.

\section{THE LAW-MAKING PROCESS}

International environmental law-making is characterized by 'autonomous institutional arrangements', with treaty bodies playing a fundamental role in development and interpretation of the law. ${ }^{88}$ Even by these standards, the ten years long regulatory odyssey that characterized the making of REDD + features peculiarities that may hold important lessons for secondary rule-making under the Paris Agreement.

While in 2009 the Copenhagen Accord emphatically called for the 'immediate establishment' of a REDD+ mechanism, ${ }^{89}$ this statement of intention was never acted upon. UNFCCC parties were unable to agree on the establishment of an institution in charge to ensure coherence and coordination in the delivery of financial and technical support for REDD.$+{ }^{90}$ As a result, REDD+ has evolved without any overall institutional oversight.

Again, a comparison with the CDM architecture is revealing. The Kyoto Protocol specifically entrusted the COP serving as the Meeting of the Parties to the Protocol to develop the rules

\footnotetext{
${ }^{88}$ As explained in R. Churchill and G. Ulfstein, 'Autonomous Institutional Arrangements in Multilateral Environmental Agreements: A Little-Noticed Phenomenon in International Law', 94:4 American Journal of International Law (2000), 623.

${ }^{89}$ Decision 2/CP.15, n. 2 above, at paragraph 6.

${ }^{90}$ UNFCCC, Coordination of Support for the Implementation of Activities in Relation to Mitigation Actions in the Forest Sector by Developing Countries, Including Institutional Arrangements (UN Doc. FCCC/SB/2013/L.5, 16 November 2013), Option 2.
} 
on the functioning of the $\mathrm{CDM},{ }^{91}$ initiating sizeable institution-building and secondary rulemaking processes concerning the governance of the CDM, including rules on the creation of carbon credits. Nothing of the kind has happened in relation to REDD+.

Instead, the REDD+ architecture is enshrined in COP decisions, which largely convey the idea of soft guidance and only rarely assume the connotation of legally binding requirements. ${ }^{92}$ This guidance has been complemented and supplemented by law-making activities and standard-setting activities carried out outside the scope of the climate regime, involving international agencies ${ }^{93}$ established beyond its institutional remit, and voluntary certification initiatives by non-State actors. This array of instruments is relevant because of the normative consequences that States and intergovernmental organizations attach to them. ${ }^{94}$ As a result, State and non-State actors operating beyond the UNFCCC, and with no formal relation to it, have progressively filled in the governance vacuum on REDD+.

As far as State action is concerned, numerous developing countries have undertaken to create the conditions to perform REDD+ activities, by adhering to bilateral and multilateral initiatives. So while no results-based payments have been made, a myriad of arrangements to create the enabling conditions for REDD+ activities exist. According to an unofficial compilation, at the time of writing a total of 1,294 REDD+ arrangements have been stipulated, including both inter-State agreements, as well as agreements between States and international organizations. ${ }^{95}$

At the bilateral level, some developed and developing country parties to the UNFCCC have concluded agreements concerning the provision of finance for REDD + . These arrangements have taken disparate forms. Norway, for example, has undertaken a 'payment-for-

\footnotetext{
${ }^{91}$ Kyoto Protocol, n. 5 above, Article 12.7.

${ }^{92}$ See in this connection the reflections in A. Savaresi, 'The Legal Status and Role of Safeguards', in: C. Voigt, n. 13 above, 126 .

${ }^{93}$ For a definition of international agencies, see A. Berman and R.A. Wessel, 'The International Legal Form and Status of Informal International Lawmaking Bodies: Consequences for Accountability', in: J. Pauwelyn et al. (eds.), Informal International Lawmaking (Oxford University Press, 2012), 35, at 44.

${ }^{94}$ On the legal value to be attached to this kind of standards, see L. Boisson de Chazournes, 'Policy Guidance and Compliance: The World Bank Operational Standards', in: D. Shelton (ed.) Commitment and Compliance: The Role of Non-Binding Norms in the International Legal System (Cambridge University Press, 2000), 282.

${ }^{95}$ See: $<$ www.reddplusdatabase.org $>$.
} 
performance' approach, thereby the size of donations is commensurate to partner countries' success in reducing emissions from deforestation. ${ }^{96}$ Other bilateral initiatives - such as those of Germany, ${ }^{97}$ and the United States ${ }^{98}$ - have not done so. ${ }^{99}$ These bilateral arrangements have engendered a legal landscape that is highly fragmented, both in form and in substance, ${ }^{100}$ and characterized by reliance upon aid to support REDD+ activities. ${ }^{101}$

At the multilateral level, two international agencies have dominated the law-making process on REDD+: the United Nations Collaborative Programme on Reducing Emissions from Deforestation and Forest Degradation (UN-REDD); ${ }^{102}$ and the World Bank's Forest Carbon Partnership Facility (FCPF). ${ }^{103}$ These international agencies have entered into agreements with a large number of UNFCCC parties willing to undertake REDD+ activities, adopting standards interpreting and filling with more precise content the rules and guidance adopted by the UNFCCC COP. In doing so, these agencies have worked as de facto alternative lawmaking forums. ${ }^{104}$ Although the FCPF and the UN-REDD standards are mere internal rules, their incorporation into partnerships and borrowing agreements makes them a crucial source of legal obligations for partner countries and a determinant factor in the emerging body of law on REDD+. ${ }^{105}$ These standards have become a main source of internationally coordinated guidance for UNFCCC parties that have partnered up with either the FCPF or the UN-REDD, or both. ${ }^{106}$ And while finance provided by means of the UN-REDD partnership agreements is akin to official development assistance, the FCPF explicitly requires the transfer of titles for

\footnotetext{
${ }^{96}$ Memorandum of Understanding between the Government of the Kingdom of Norway and the Government of Brazil (16 September 2008), Article 2(b).

${ }_{97}^{97}$ GIZ, 'Forests and Climate Change Programme'; see: $<$ http://www.forclime.org/en/>.

${ }^{98} \mathrm{See}<$ https://www.usaid.gov/climate/sustainable-landscapes $>$.

${ }^{99}$ As noted also in C. Streck and C. Parker, n. 56 above, at 117.

${ }^{100}$ As noted also in A. Dibler et al., n. 49 above, at 51.

${ }^{101}$ See A. Angelsen and D. McNeill, n. 56 above, at 39.

${ }^{102}$ FAO, UNDP and UNEP, 'UN Collaborative Programme on Reducing Emissions from Deforestation and Forest Degradation in Developing Countries (UN-REDD) Framework Document' (2008). At the time of writing, the programme has 64 partner countries: <www.un-redd.org/Partner_Countries/tabid/102663/Default.aspx>.

${ }^{103}$ World Bank, Charter Establishing the Forest Carbon Partnership Facility (2013 edition). At the time of writing, 47 countries participate in the FCFP: <www.forestcarbonpartnership.org/redd-country-participants>.

${ }^{104}$ As argued also in A. Savaresi, 'The Role of REDD in Harmonising Overlapping International Obligations', in: E. Hollo et al., n. 25 above, 391.

${ }_{105}$ As suggested in L. Boisson de Chazournes, n. 94 above.

${ }^{106}$ At the time of writing, 44 UNFCCC parties have partnered with both with the FCPF and the UN-REDD.
} 
emission reduction credits. ${ }^{107}$ More generally, divergence in standards by the FCPF and the UN-REDD has resulted in the fact that the same activities in the same countries may be subjected to different standards, depending on which institution is handling the funding. This chasm in the approach to REDD+ is hardly conducive to the establishment of a level playing field enabling countries to carry out REDD+ activities on an equal footing. ${ }^{108}$

Finally, non-State actors have also contributed to the composite legal landscape on REDD+ by elaborating standards for the voluntary certification of REDD+ activities. ${ }^{109}$ International as well as local nongovernmental organizations have actively developed, implemented and invested in REDD+ demonstration projects. ${ }^{110}$ Even though these endeavours have been seemingly undercut by the adoption of a jurisdictional approach to REDD+, ${ }^{111}$ for the time being some finance to facilitate the involvement of non-State actors in REDD+ activities has been made available. ${ }^{112}$

This diverse set of actors has given life to a range of separate and only intermittently communicating formal and informal law-making processes, which have produced multifarious legal outcomes. This proliferation of law-making endeavours has been necessitated by events and does not seem to augur well for the overall coherence of REDD+. Indeed, studies on the implementation of REDD+ have evidenced concerns over this state of affairs. ${ }^{113}$ Rather than the outcome of a 'smart design', this heterogeneous collection of processes and outcomes is the result of what may be regarded as a renunciation of lawmaking authority by the UNFCCC parties. Other forums have consequently attempted to

107 FCPF Carbon Fund Methodological Framework (20 December 2013), found at: $<$ http://www.forestcarbonpartnership.org/carbon-fund-methodological-framework $>$.

${ }_{108}$ As argued also in A. Savaresi, n. 92 above.

${ }^{109}$ See: Climate, Community and Biodiversity Alliance, Climate, Community and Biodiversity Project Design Standards. (December 2008 Edition), found at: <www.climate-standards.org/ccb-standards/>; and VCS, Agriculture and Forestry Projects, found at: <http://www.v-c-s.org/develop-project/agriculture-forestryprojects $>$. Standards that are not aimed at certification have also been elaborated. See Climate, Community and Biodiversity Alliance and CARE, REDD+ Social \& Environmental Standards, (September 2012 Edition), found at: <www.redd-standards.org/>.

${ }^{110}$ See A. Angelsen and D. McNeill, n. 56 above, at 45.

${ }^{111}$ As suggested in M. Dutschke, 'REDD+: Time to Lay the Nested Approach to Rest?' (20 February 2016), found at: $<$ https://www.linkedin.com/pulse/redd-time-lay-nested-approach-rest-michael-dutschke $>$.

112 Such as the Community-Based REDD+ funds by the UN-REDD. See <http://www.unredd.org/CommunityBasedREDDLaunch/tabid/133356/Default.aspx $>$.

${ }^{113}$ See, e.g., Norad, Real-Time Evaluation of Norway's International Climate and Forest Initiative. Synthesising Report 2007-2013 (Norad, 2014), at xxiv and xxviii. 
address the various regulatory needs engendered by REDD + . Whereas this may have been an acceptable interim solution, it has progressively engendered a great deal of confusion and uncertainty. With no overall institution in charge, the bottom-up architecture on REDD+ seems to be in need for at least some orchestration to ensure the carbon integrity of REDD+ activities, the comparability between the results they deliver, as well as the most efficient use of the finite resources available to carry out REDD+ activities. ${ }^{114}$

The Paris Agreement has not significantly altered this state of affairs, but merely recognizes ex post facto the rules adopted by the UNFCCC COP,${ }^{115}$ without creating a dedicated institution in charge of overseeing REDD+ activities, and/or the related law-making process. Experience with REDD+ therefore seems to point to the need to carefully steer the lawmaking process to realize the bottom-up pledge and review architecture envisioned in the Paris Agreement. Like that for REDD+, the Paris Agreement architecture was sketched with no smart design in mind, and under the pressure of largely dysfunctional negotiation dynamics. The secondary rule-making season awaiting the parties to the Paris Agreement provides an opportunity to build the elements of this new architecture rationally, learning from lessons accrued, amongst others, with REDD+. Some further reflections in this connection are provided in the conclusions.

\section{CONCLUSIONS: LESSONS FROM THE REDD+ ODYSSEY}

This article has reflected on the bottom-up pledge-and-review architecture that characterizes REDD+, using it as a point of reference to predict challenges likely to emerge in the implementation of the Paris Agreement. The REDD+ architecture remains little tested in practice. The related legal landscape is characterized by a great deal of regulatory and institutional fragmentation, as well as uncertainty. Fundamental elements of this architecture remain undefined, most saliently those to enable a market-based approach to finance REDD+

\footnotetext{
${ }^{114}$ An in-depth reflection on coordination needs amongst REDD+ initiatives can be found in E. Recio, 'The Warsaw Framework and the Future of REDD+', 24 Yearbook of International Environmental Law (2013) 37, at 65 .

${ }^{115}$ Paris Agreement, n. 1 above, Article 5.2.
} 
activities; the review of implementation of parties' obligations; and the coordination of the law-making process.

The analysis carried out in this article has evidenced the need to strengthen existing rules to ensure the carbon integrity of REDD+ emission reductions and removals, and the review of implementation of parties' action in a way that is in line with the transparency framework to be drawn up under the Paris Agreement. This is especially necessary if a market-based approach to REDD+ finance is adopted, which would in turn require the establishment of conditions to ensure the tradability and fungibility of REDD+ credits.

This article has argued that, compared with those under the Kyoto Protocol, transparency and review arrangements concerning REDD + are rather patchy. The comparatively more rigorous arrangements under the Kyoto Protocol seem better suited to ensure the carbon integrity of mitigation activities. In an ideal world, it would seem logical for the parties to Paris Agreement to build upon rules developed under the Kyoto Protocol, rather than the looser facilitative review processes and the limited reporting obligations elaborated under the UNFCCC. If anything, rules and review processes under the Kyoto Protocol ought to be scaled up to apply to all parties, after having been reformed to address shortcomings that have become apparent in their implementation. Whether parties to the Paris Agreement will have the political will necessary to build such a robust framework, however, remains to be seen.

Finally, experience with REDD+ seems to hold important lessons for the international lawmaking process associated with the implementation of the Paris Agreement. It seems vital that parties to the Paris Agreement maintain in control of the making of rules on matters for which intergovernmental coordination is required. One such area is the reporting of information concerning emissions and removals, which needs to align with rigorous and homogenous rules and review procedures applicable to all, in order to ensure the carbon integrity of the climate regime. Another area where some coordination seems indispensable is the establishment of a regulatory framework to enable a market-based approach to climate change mitigation. Experience with extant carbon markets has revealed concerns over double 
counting and leakage. The secondary rules adopted under the Paris Agreement should tackle these risks head-on, establishing common parameters to ensure the integrity of emission trading. In this process, parties should resolutely resort to Ockham's razor to tackle the institutional proliferation that plagues the climate regime, discarding processes and institutions that are no longer needed. The history of international climate change law-making thus far indicates that crafting these rules is unlikely to be easy or quick. The adoption of the Paris Agreement is but the beginning of a new, predictably lengthy regulatory odyssey. Parties to the Paris Agreement are not without maps and charts to navigate the predictably choppy waters expecting them. The experience they have accrued in years of negotiations on REDD + will hopefully serve them as a guide in this new, exciting and perilous journey.

Annalisa Savaresi is Research and Teaching Fellow in Global Environmental Law at the University of Edinburgh Law School. She is a member of the International Union for the Conservation of Nature (IUCN) World Commission on Environmental Law and has served as a consultant for numerous international organizations, including working as writer for the Earth Negotiation Bulletin published by the International Institute for Sustainable Development. 